\title{
Simultaneous Quantification of Bergenin, (+)-Catechin, Gallicin and Gallic acid; and quantification of $\beta$-Sitosterol using HPTLC from Bergenia ciliata (Haw.) Sternb. Forma ligulata Yeo (Pasanbheda)
}

Rathee Dharmender ${ }^{1}$, Thanki Madhavi ${ }^{1}$, Agrawal Reena $^{2}$ and Anandjiwala Sheetal ${ }^{1 *}$

${ }^{1}$ Dept. of Natural Products, National Institute of Pharmaceutical Education and Research, Ahmedabad, Gujarat, India ${ }^{2}$ B. V. Patel Pharmaceutical Education Research Development Centre, Thaltej, Ahmedabad - 380 054; Gujarat, India

\begin{abstract}
In the present paper we report our work on development and validation of TLC densitometric method for simultaneous quantification of Bergenin, (+)-Catechin, Gallicin and Gallic acid, and quantification of $\beta$-Sitosterol using HPTLC.To the best of our knowledge, this is the first report of simultaneous quantification of these four bioactive compounds viz. Bergenin, (+)-Catechin, Gallicin and Gallic acid using HPTLC from this plant. Simultaneous quantification of Bergenin, $(+)$-Catechin, Gallicin and Gallic acid was carried out from the methanolic and hydrolysed extract $(2 \mathrm{~N} \mathrm{HCl})$ using the Solvent System of Toluene: Ethyl acetate: Formic acid (6: $6: 1, \mathrm{v} / \mathrm{v} / \mathrm{v})$. $\beta$-Sitosterol was quantified from petroleum ether extract using the Solvent System of Toluene : Methanol (9: 1, v/v). The methods were validated using ICH guidelines in terms of precision, repeatability and accuracy. The thin layer chromatography densitometric methods were found to be precise with RSD for intra-day in the range of 2.62-4.26, 0.35-2.5, 0.61-1.83, 1.14-1.57 and $0.15-0.52$ and for interday in the range of $1.90-4.27,0.85-3.05,0.97-1.45,0.58-1.27$ and $0.26-0.61$ for different concentrations of Bergenin, (+)-Catechin, Gallicin, Gallic acid and $\beta$-Sitosterol respectively. The linearity ranges for Bergenin, $(+)$-Catechin, Gallicin and Gallic acid were found to be the same (160-720 ng/spot) with correlation coefficients ( $r$-values) of $0.999,0.997,0.998$ and 0.996 respectively. The linearity range for $\beta$-Sitosterol was $80-480 \mathrm{ng} / \mathrm{spot}$ with correlation coefficient ( $r$-values) of 0.995 . Instrumental precision was 3.39, 3.36, 3.05, 1.20 and 0.85 (\% RSD) for Bergenin, (+)-Catechin, Gallicin, Gallic acid and $\beta$-Sitosterol respectively. Accuracy of the method was checked by conducting recovery studies at three different levels for both the compounds and the average percentage recoveries obtained were 100.38, 101.45, 102.38, 99.9 and $99.92 \%$ respectively for Bergenin, (+)-Catechin, Gallicin, Gallic acid and -Sitosterol. The amount of Bergenin, (+)-Catechin and Gallic acid was $0.22,0.063$ and $0.25 \% \mathrm{w} / \mathrm{w}$ respectively whereas Gallicin was not in detectable amount. Developed method permitted simultaneous quantification of Bergenin, (+)-Catechin, Gallicin and Gallic acid, and showed good resolution and separation from other constituents of extract and was found to be simple, precise, specific, sensitive and accurate. It can be adopted for routine quality control of herbal material and formulations containing Bergenia ciliata.
\end{abstract}

Keywords: Bergenia ciliata; Bergenin; (+)-Catechin; Gallicin; Gallic acid; $\beta$-Sitosterol; HPTLC.

\section{Introduction}

Bergenia ciliata (Haw.) Sternb. forma ligulata Yeo. (syn. Saxifraga ligulata Wall., B. ligulata(Wall) Engl.); Fam. Saxifragaceae is a medicinal plant distributed in South East Asia [1]. The plant is found throughout the temperate Himalayas from Kashmir to Bhutan, between 7000 $10,000 \mathrm{ft}$. and in the Khasia hills at $400 \mathrm{ft}$. [2]. It is a reputed drug of Ayurveda, commonly known as Pasanbheda. This plant has been recognized for its action on the urinary tract since ancient times, the name Pasanbheda being descriptive of its litholytic property [3]. The rhizomes have been used for centuries in Ayurvedic formulations for various ailments [4]. It has been used as a poultice, for treating boils, for curing diarrhea and vomiting, for treatment of fever, cough, menorrhagia, excessive uterine hemorrhage and pulmonary infections $[5,6]$. The rhizome is bruised and applied to boils, in ophthalmia, in eyesore and also used as anthelmintic [5, 7]. The marketed composite herbal formulations, Cystone (Himalaya Drug Company, India), Calcuri (Charak Pharmaceuticals, Bombay, India) and Chandraprabha Vati (Baidyanath, India) have been widely used clinically to dissolve urinary calculi in the kidney and urinary bladder [8]. Alcoholic extracts of plant exhibited significant anti-inflammatory, analgesic and diuretic properties [9] and antiurolithiatic activity [8]. Methanolic extract of rhizome showed significant inhibition of cough reflex [10] and exhibited a broad spectrum of antibacterial activity [11]. The major chemical constituents reported from B. ciliata are 11-O-galloyl
Bergenin [12], Bergenin (1) and its glycosides, (+)-Catechin (2), Methyl Gallate (Gallicin) (3), Gallic acid (4) and leucocyanidin [13], (+)-Catechin-3-gallate [14], (+)-Catechin-7-O- $\beta$-D-glucopyranoside [12] and Paashaanolactone [15]. $\beta$-Sitosterol (5), $\beta$-Sitosterol- $D$ glucoside [16], (+)-Afzelechin [17].

Nowadays, HPTLC has become a routine analytical technique due to its advantages of reliability in quantitation of analytes at micro and even in nanogram levels and cost effectiveness [18]. It has proved a very useful technique because of its low operating cost, high samplethroughput and need for minimum sample clean-up. The major advantage of HPTLC is in reducing analysis time and cost per analysis.

*Corresponding author: Dr. Sheetal Anandjiwala, Dept. of Natural Products, NIPER-Ahmedabad, B. V. Patel Pharmaceutical Education and Research Development (PERD) Centre, Thaltej-Gandhinagar Highway, Thaltej, Ahmedabad -380054, Gujarat, India, Fax: +91-79-27450449; E-mail: drsheetalanand@yahoo. $\underline{\text { co.in }}$

Received August 26, 2010; Accepted September 22, 2010 Published September 25,2010

Citation: Dharmender R, Madhavi T, Reena A, Sheetal A (2010) Simultaneous Quantification of Bergenin, (+)-Catechin, Gallicin and Gallic acid; and quantification of $\beta$-Sitosterol using HPTLC from Bergenia ciliata (Haw.) Sternb. Forma ligulata Yeo (Pasanbheda). Pharm Anal Acta 1:104. doi:10.4172/2153-2435.1000104

Copyright: ( 92010 Dharmender R, et al. This is an open-access article distributed under the terms of the Creative Commons Attribution License, which permits unrestricted use, distribution, and reproduction in any medium, provided the original author and source are credited. 
Citation: Dharmender R, Madhavi T, Reena A, Sheetal A (2010) Simultaneous Quantification of Bergenin, (+)-Catechin, Gallicin and Gallic acid; and quantification of $\beta$-Sitosterol using HPTLC from Bergenia ciliata (Haw.) Sternb. Forma ligulata Yeo (Pasanbheda). Pharm Anal Acta 1:104. doi:10.4172/2153-2435.1000104

Unlike HPLC, for which substantial amounts of mobile phase and long analysis times are required for quantification of multiple samples, HPTLC has the advantage that several samples can be estimated simultaneously using a small quantity of mobile phase. HPTLC also has the advantage of providing visualization of the separated constituents of the sample. It also provides on line identification of the analyte by in-situ spectrum scanning and post chromatographic derivatization, along with $\mathrm{Rf}$ comparison with the standard. It requires very little sample clean up since the layer is disposable. Several samples can be run simultaneously using a small quantity of mobile phase, thus reducing the time and cost per analysis. Due to low consumption of solvent the methodology is eco friendly. Another advantage of HPTLC is that several samples can be analyzed simultaneously using a small quantity of mobile phase unlike HPLC. This reduces the time and cost of analysis and possibilities of pollution of the environment. HPTLC also facilitates repeated detection (scanning) of the chromatogram with same or different parameters. Simultaneous assay of several components in a multicomponent formulation is also possible. Due to several advantages, such as the rapidity, the fewer amounts of sample, and an extremely limited solvent waste, HPTLC has gained widespread interest as a favorable technique for the determination of pharmacologically interesting compounds in biological matrices, such as plants, leaves, and flowers and herbal formulations [19-24]. A number of high performance liquid chromatography (HPLC) which need sample cleanup to remove the interfering constituents in the plant extracts, making the procedure more tedious and unsuitable for screening large number of samples. Recently, high performance thin layer chromatography (HPTLC) has been widely employed for the quantification of secondary metabolites [25-30].

Some of the analytical methods reported for the qualitative and quantitative analysis of Bergenin, Gallic acid and Catechin from $B$. ligulata are discussed herewith. Chauhan et al. [31] and Srivastava et al. [32] reported a method for determination of Bergenin and Gallic acid from B. ligulata and in different Bergenia species using HPTLC, but there are no report of simultaneous quantification of bergenin, gallic acid, catechin and gallicin. Yu et al. [33] also repoted a method for quantitation of bergenin in human plasma by LC-MS/MS. Reddy et al. [34] reported the determination of Bergenin and (+) -Afzelechin from different parts of Paashaanbhed (Bergenia ligulata Yeo) by HPLC using C18 column. Dhalwal et al. [35] repoted the Simultaneous quantification of bergenin, catechin and gallic acid from Bergenia ciliata and Bergenia ligulata by using TLC but there is no report of simultaneous quantification of the four major biomarkers present in this plant i.e. bergenin, gallic acid, catechin and gallicin, further the quantification of $\beta$-Sitosterol is also reported for the first time from this plant. Shi et al. [36] and Wang et al. [37] developed and reported the methods for determination and pharmacokinetic study of bergenin in biological fluid i.e. rat plasma by RP-HPLC method and Nunomura et al. [38] also reported the determination of bergenin by RP-HPLC method. HPLC determination of bergenin in different Bergenia species was also done by Singh et al. [39].

In the present paper, we report our work on quantification of five marker compounds viz., Bergenin, (+)-Catechin, Gallicin, Gallic acid and $\beta$-Sitosterol by HPTLC (structures. Figure 1 ) at the same wavelength $(\lambda$ max $280 \mathrm{~nm}$ ) from the rhizomes of $B$. ligulata. Gallicin was quantified densitometrically from the methanolic extract but Bergenin, (+)-Catechin and Gallic acid as present in bound form were quantified from the hydrolysed extract $(5 \mathrm{~N}$ methanolic $\mathrm{H}_{2} \mathrm{SO}_{4}$ ). We developed TLC densitometric methods for simultaneous quantification of Bergenin, (+)-Catechin, Gallicin, Gallic acid and

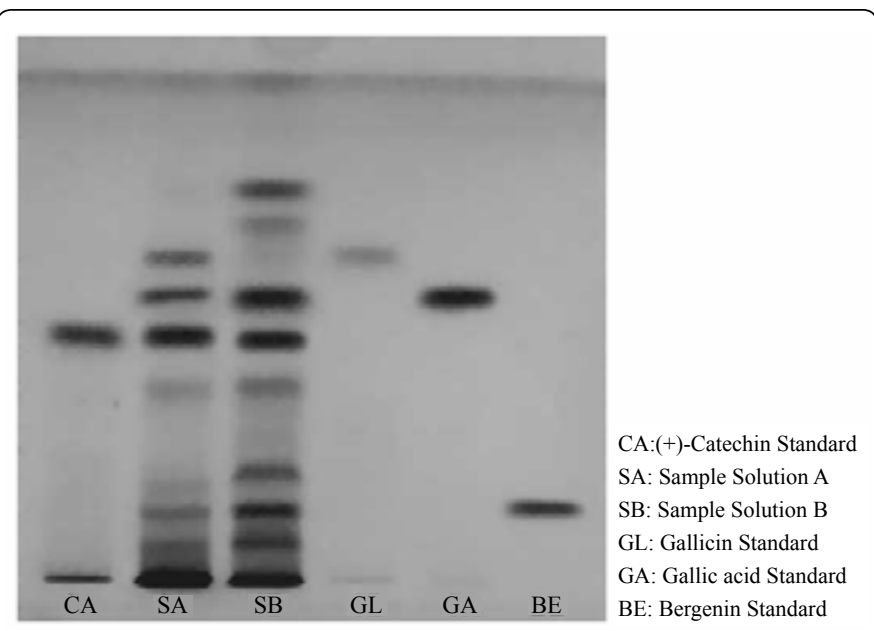

Figure 1: TLC fingerprint profile of Bergenia ciliata Rhizome under UV $254 \mathrm{~nm}$ (Sample Solution A and B, Solvent System 1).

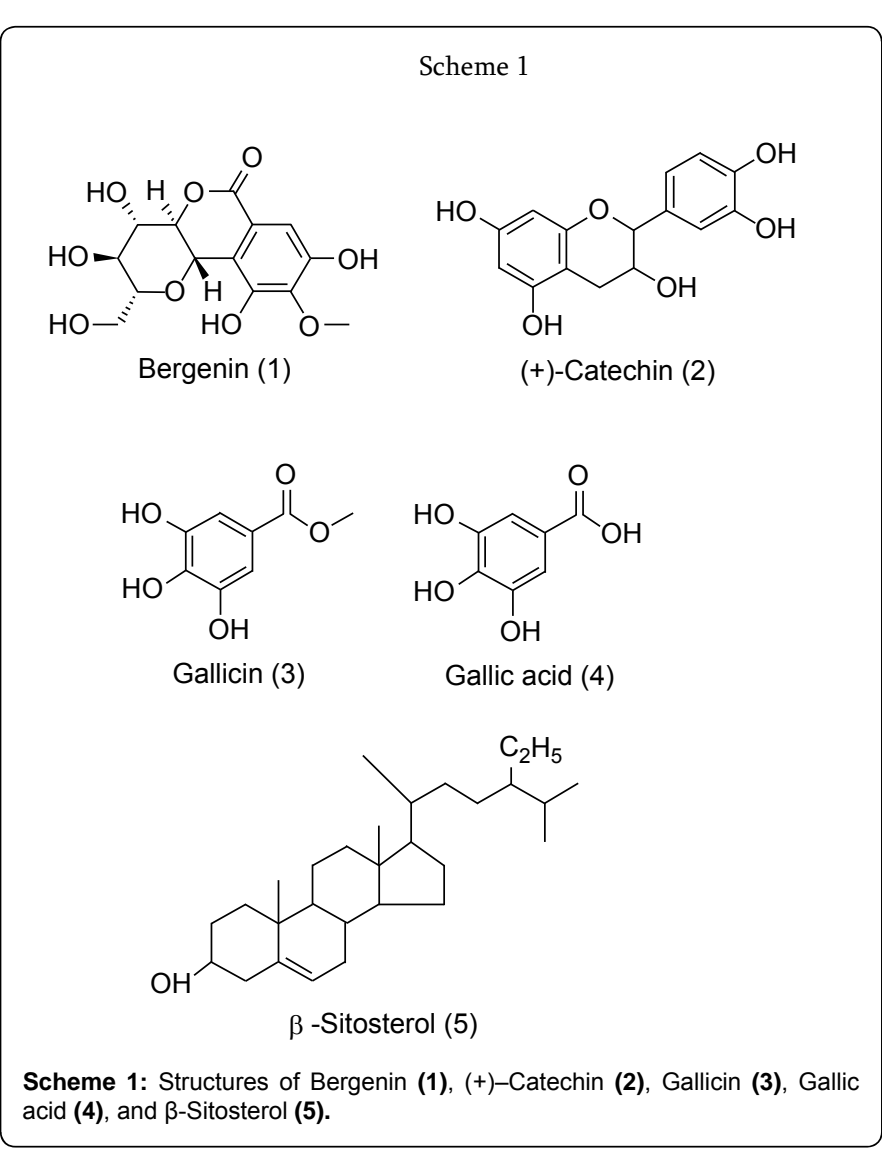

quantification of $\beta$-Sitosterol. To the best of our knowledge this is the first report of simultaneous quantification of Bergenin, (+)-Catechin, Gallicin and Gallic acid from B. ligulata. Furthermore, no TLC densitometric methods have been reported for the quantification of $\beta$-Sitosterol from $B$. ligulata. These five compounds have been shown to have significant pharmacological activities. Bergenin is reported to have hepatoprotective [40], and immunomodulatory [41] activity. (+)-Catechin has been shown to have antioxidant [42], glucosidase-II [43] and matrix metalloproteinase inhibitory activity [44] and renoprotective effect [45]. It has also been reported to induce cancer preventive activity mediated through a chaperone 
Citation: Dharmender R, Madhavi T, Reena A, Sheetal A (2010) Simultaneous Quantification of Bergenin, (+)-Catechin, Gallicin and Gallic acid; and quantification of $\beta$-Sitosterol using HPTLC from Bergenia ciliata (Haw.) Sternb. Forma ligulata Yeo (Pasanbheda). Pharm Anal Acta 1:104. doi:10.4172/2153-2435.1000104

like property [46]. Gallicin is reported to have antioxidant [47], antitumor [48] antiplatelet [49], antimicrobial [50], anti-inflammatory and cyclooxygenase-2/5-lipoxygenase inhibitory [51] activity. Gallic acid has been shown to have antioxidant $[52,53]$, anti-inflammatory, cytotoxic and bactericidal activity [53], gastric protective action [53] and antiangiogenic activity [54]. $\beta$-Sitosterol is reported to show antioxidant [55], anti-inflammatory [56], analgesic and anthelmintic [57] activity. It is also found to be effective in the treatment of benign prostatic hyperplasia [58].

We developed a simple TLC densitometric method for the simultaneous quantification of Bergenin, Gallic acid, Gallicin and $(+)$-Catechin and also report the quantification of $\beta$-Sitosterol from $B$. ligulata. For quantification of Bergenin and (+)-Catechin, we developed the method, whereas for the quantification of Gallic acid [59-63], Gallicin [59] and $\beta$-Sitosterol [59] we adopted the methods reported earlier from our laboratory with some modifications to suit the sample. The present work describes a simple yet sensitive, specific, and reproducible HPTLC method for the quantification of Bergenin, Gallic acid, Gallicin and (+)-Catechin and also for $\beta$-Sitosterol in B. ligulata rhizomes.

\section{Materials and Methods}

\section{Plant material}

Rhizome of $B$. ciliata was procured from the market in Jamnagar Dist. Gujarat, India. It was authenticated by our taxonomist and a voucher specimen (NIPER-A/NP/0408/02) was preserved in the Dept. of Natural Products. The plant material was dried in a hot air oven at $<50$ $\mathrm{C}$, stored in airtight glass bottle at $30^{\circ} \mathrm{C}$ and powdered to 40 mesh whenever required.

\section{Chemicals}

All the solvents of analytical grade were purchased from Qualigens Fine Chemicals, Mumbai, India. Bergenin (Purity: 98\% w/w), (+)-Catechin (Purity: 98\% w/w) and $\beta$-Sitosterol (Purity: 97\% w/w) were purchased from Natural Remedies Pvt. Ltd, Bangalore, India. Gallicin (Purity: 98\% w/w) was purchased from ICN Biomedicals, USA; Gallic acid (Purity: $99 \% \mathrm{w} / \mathrm{w}$ ) was a gift sample from Tetrahedron Ltd, India.

\section{TLC conditions}

The TLC plates were $20 \times 10 \mathrm{~cm}$, precoated with silica gel $60 \mathrm{~F}_{254}$ TLC plates (E. Merck) (0.2 mm thickness); spotting device was Camag Linomat V Automatic Sample Spotter, Camag (Muttenz, Switzerland); syringe was a $100 \mu \mathrm{L}$ (Hamilton); developing chamber was a CAMAG glass twin trough chamber $(20 \times 10 \mathrm{~cm})$; densitometer a Camag TLC Scanner 3 linked to winCATS software. Experimental conditions: Temperature $25 \pm 2^{\circ} \mathrm{C}$, relative humidity $40 \%$.

\section{TLC fingerprinting profile}

Sample solutions: Preparation of Sample Solution was optimized to achieve good fingerprinting and also to extract the marker compounds efficiently. Of these, the preparations of selected sample solutions were:

A. Methanolic extract: Since all the five marker compounds were soluble in methanol, we prepared methanolic extract. Accurately weighed $1 \mathrm{~g}$ of the powdered drug was extracted with methanol $(25 \mathrm{~mL} \times 4)$ under reflux on a water bath. The methanolic extract was filtered through Whatman I filter paper, filtrates were combined, concentrated under vacuum and the volume was made upto $25 \mathrm{~mL}$ in a volumetric flask (Sample Solution A). This extract was used for TLC fingerprinting and co-chromatography with marker compounds.

B. Hydrolyzed extract: Bergenin, (+)-Catechin, Gallic acid and $\beta$-Sitosterol are reported to be present in bound form in the drug. Hence we subjected the drug to hydrolysis by the following procedure: Accurately weighed $2 \mathrm{~g}$ of the powdered drug was hydrolyzed with $2 \mathrm{~N}$ aqueous hydrochloric acid $(50 \mathrm{~mL})$ under reflux on a water bath for 2 hours at $100^{\circ} \mathrm{C}$. The extract was filtered through Whatman I filter paper and the marc was washed with minimum amount of double distilled water $(\sim 5$ to $6 \mathrm{~mL})$ and filtered. The combined filtrates were transferred to a separating funnel and further extracted with ethyl acetate $(25 \mathrm{~mL} \times 4)$, dried over sodium sulphate, pooled, concentrated and the volume was made upto $25 \mathrm{~mL}$ with ethyl acetate (Sample Solution B). This extract was used for TLC fingerprinting and co-chromatography with Bergenin, (+)-Catechin and Gallic acid.

Standard solutions of bergenin, $(+)$-catechin, gallicin, gallic acid and $\beta$-sitosterol

$2 \mathrm{mg}$ each of Bergenin, (+)-Catechin, Gallicin, Gallic acid and $\beta$-Sitosterol were dissolved separately in methanol and the volume was made upto $25 \mathrm{~mL}$ with methanol in volumetric flasks individually.

\section{Solvent systems}

Two Solvent Systems were used for chromatographic separation.

Solvent System I- Toluene: Ethyl acetate: Formic acid (6: 6: 1, $\mathrm{v} / \mathrm{v} / \mathrm{v})$ for co-chromatography with Bergenin, (+)-Catechin, Gallicin and Gallic acid.

Solvent System II- Toluene: Methanol (9: 1, v/v) for cochromatography with $\beta$-Sitosterol.

\section{Procedure}

For co-chromatography with Bergenin, (+)-Catechin, Gallicin and, Gallic acid, $10 \mu \mathrm{L}$ each of Sample Solution A and B along with the standards were applied on a TLC plate and the plate was developed in Solvent System I to a distance of $8 \mathrm{~cm}$. The plates were observed under UV $254 \mathrm{~nm}$ and $U V 366 \mathrm{~nm}$. The $\mathrm{R}_{\mathrm{f}}$ values of resolved bands were noted. The identity of the bands of Bergenin, (+)-Catechin, Gallicin and Gallic acid in the sample track were confirmed by overlaying their UV absorption spectra with those of the respective reference standards using a Camag TLC Scanner 3 with winCATS software. The purity of each of these bands in the sample extract track was checked by comparing the absorption spectra recorded at start, middle and end positions of each of the band.

For co-chromatography with $\beta$-Sitosterol, $10 \mu \mathrm{L}$ each of Sample Solution A along with the standard was applied on a TLC plate and the plate was developed in Solvent System II to a distance of $8 \mathrm{~cm}$. The plates were dried at room temperature in air and derivatized with anisaldehyde-sulphuric acid reagent and heated at $105^{\circ}$ for 5 $\min$. The $R_{f}$ values and colour of the resolved bands were noted.

\section{TLC densitometric quantification of Bergenin, (+)-Catechin, Gallicin and Gallic acid using HPTLC}

Sample solution-1 (methanolic extract): Sample Solution-A described under the previous section was used for simultaneous quantification of Bergenin, (+)-Catechin, Gallicin and Gallic acid.

Sample solution-2 (prepared by hydrolysis of drug): Sample Solution-B described under the previous section was used for quantification of Bergenin, (+)-Catechin and Gallic acid. 
Citation: Dharmender R, Madhavi T, Reena A, Sheetal A (2010) Simultaneous Quantification of Bergenin, (+)-Catechin, Gallicin and Gallic acid; and quantification of $\beta$-Sitosterol using HPTLC from Bergenia ciliata (Haw.) Sternb. Forma ligulata Yeo (Pasanbheda). Pharm Anal Acta 1:104. doi:10.4172/2153-2435.1000104

Preparation of standard solutions of bergenin, (+)-catechin, gallicin and gallic acid: Stock solution of $80 \mu \mathrm{g} / \mathrm{mL}$, each of Bergenin, $(+)$-Catechin, Gallicin and Gallic acid were prepared by dissolving 4 mg each of accurately weighed Bergenin, (+)-Catechin, Gallicin and Gallic acid separately in methanol and making up the volume of the solutions to $50 \mathrm{~mL}$ with methanol in volumetric flasks. The aliquots ( 2 to $9 \mathrm{~mL}$ ) of stock solutions were transferred to $10 \mathrm{~mL}$ volumetric flasks and the volume of each was adjusted to $10 \mathrm{~mL}$ with methanol, to obtain standard solutions containing $16 \mu \mathrm{g} / \mathrm{mL}, 24 \mu \mathrm{g} / \mathrm{mL}, 32$ $\mu \mathrm{g} / \mathrm{mL}, 40 \mu \mathrm{g} / \mathrm{mL}, 48 \mu \mathrm{g} / \mathrm{mL}, 56 \mu \mathrm{g} / \mathrm{mL}, 64 \mu \mathrm{g} / \mathrm{mL}$ and $72 \mu \mathrm{g} / \mathrm{mL}$ of Bergenin, (+)-Catechin, Gallicin and Gallic acid respectively.

\section{Preparation of calibration curve of Bergenin (+)-Catechin,} Gallicin and Gallic acid: $10 \mu \mathrm{L}$ each of the

standard solutions of Bergenin, (+)-Catechin, Gallicin and Gallic acid (160 to $720 \mathrm{ng} / \mathrm{spot}$ ) were applied (band width: $6 \mathrm{~mm}$, distance between the tracks: $12 \mathrm{~mm}$ ) in triplicates on a TLC plate using automatic sample spotter. The plates were developed in a twin trough chamber $(20 \times 10 \mathrm{~cm})$ upto a distance of $8 \mathrm{~cm}$ using a Solvent System of Toluene : Ethyl acetate : Formic acid $(6: 6: 1, \mathrm{v} / \mathrm{v} / \mathrm{v})(13 \mathrm{~mL})$ at $25 \pm$ $2{ }^{\circ} \mathrm{C}$ temperature and $40 \%$ relative humidity. The plates were dried at room temperature and scanned at $280 \mathrm{~nm}$ in absorbance mode using deuterium lamp. The areas of the resolved peaks were recorded. Calibration curve of Bergenin, (+)-Catechin, Gallicin and Gallic acid was obtained by plotting peak areas vs applied concentrations of Bergenin, (+)-Catechin, Gallicin and Gallic acid respectively.

Simultaneous quantification of bergenin, $(+)$-catechin, gallicin and gallic acid in the samples: The solvent system was optimized to Toluene: Ethyl acetate: Formic acid $(6: 6: 1 \mathrm{v} / \mathrm{v} / \mathrm{v}) .10 \mu \mathrm{L}$ each of suitably diluted Sample Solution -1 and -2 along with the marker compounds were applied in triplicate on a TLC plate. The plate was developed in the given Solvent system and scanned as mentioned above. The peak areas and absorption spectra were recorded and the amount of Bergenin, (+)-Catechin, Gallicin and Gallic acid were calculated using their respective calibration curves.

\section{Quantification of $\beta$-sitosterol using HPTLC}

For the quantification of $\beta$-Sitosterol, we adopted the method reported by us earlier [59].

Sample solution-3 (petroleum ether extract): In order to reduce the interference of polar compounds, we prepared petroleum ether extract for quantification of $\beta$-Sitosterol. $1 \mathrm{gm}$ of powdered drug was extracted with petroleum ether $(25 \mathrm{~mL} \times 4)$ under reflux. The extract was filtered, pooled, concentrated and the volume was made upto 25 $\mathrm{mL}$ with petroleum ether.

Preparation of standard solutions of $\beta$-sitosterol: A stock solution of $\beta$-Sitosterol $(50 \mu \mathrm{g} / \mathrm{mL})$ was prepared by dissolving $5 \mathrm{mg}$ of accurately weighed $\beta$-Sitosterol in methanol and making up the volume of the solution to $100 \mathrm{~mL}$ with methanol in a volumetric flask. The aliquots ( 1.6 to $9.6 \mathrm{~mL}$ ) of the stock solution were transferred to $10 \mathrm{~mL}$ volumetric flasks and the volume of each was adjusted to 10 $\mathrm{mL}$ with methanol to obtain standard solutions containing $8 \mu \mathrm{g} / \mathrm{mL}$, $16 \mu \mathrm{g} / \mathrm{mL}, 24 \mu \mathrm{g} / \mathrm{mL}, 32 \mu \mathrm{g} / \mathrm{mL}, 40 \mu \mathrm{g} / \mathrm{mL}$ and $48 \mu \mathrm{g} / \mathrm{mL}$ of $\beta$-Sitosterol respectively.

Preparation of calibration curve of $\beta$-sitosterol: $10 \mu \mathrm{L}$ each of the standard solutions of $\beta$-Sitosterol ( 80 to $480 \mathrm{ng} / \mathrm{spot}$ ) were applied (band width: $6 \mathrm{~mm}$, distance between the tracks: $12 \mathrm{~mm}$ ) in triplicates on a TLC plate using automatic sample spotter. The plates were developed in a twin trough chamber $(20 \times 10 \mathrm{~cm})$ upto a distance of $8 \mathrm{~cm}$ using a Solvent System of Toluene: Methanol (10 $\mathrm{mL})(9: 1, \mathrm{v} / \mathrm{v})$ at $25 \pm 2^{\circ} \mathrm{C}$ temperature and $40 \%$ relative humidity. After development, the plates were dried at room temperature in air, derivatized with anisaldehyde-sulphuric acid reagent, heated at $105^{\circ}$ for $5 \mathrm{~min}$. and scanned densitometrically at $525 \mathrm{~nm}$ in absorbance mode using tungsten lamp. The area of the resolved peaks was recorded. Calibration curve of $\beta$-Sitosterol was obtained by plotting peak areas $v \boldsymbol{s}$ concentrations of $\beta$-Sitosterol applied.

Quantification of $\beta$-sitosterol in the sample: $15 \mu \mathrm{l}$ of suitably diluted Sample Solution-3 was applied in triplicates on a TLC plate. The plate was developed and scanned as mentioned above. The peak areas were recorded and the amount of $\beta$-Sitosterol was calculated using the calibration curve

\section{Validation of the methods}

ICH guidelines were followed for the validation of the analytical methods developed (CPMP/ICH/281/95 and CPMP/ICH/381/95) for precision, repeatability and accuracy.

Instrumental precision: Instrumental precision was checked by repeated scanning $(n=7)$ of the same spot of Bergenin (400ng/ spot), (+)-Catechin (400ng/spot), Gallicin (480 ng/spot), Gallic acid (480 ng/spot) and $\beta$-Sitosterol (160 ng/spot) and expressed as relative standard deviation (\% R.S.D.).

\section{Repeatability}

The repeatability of the method was affirmed by analyzing 400ng/ spot of Bergenin, 400ng/spot of (+)-Catechin, $480 \mathrm{ng} / \mathrm{spot}$ of Gallicin,

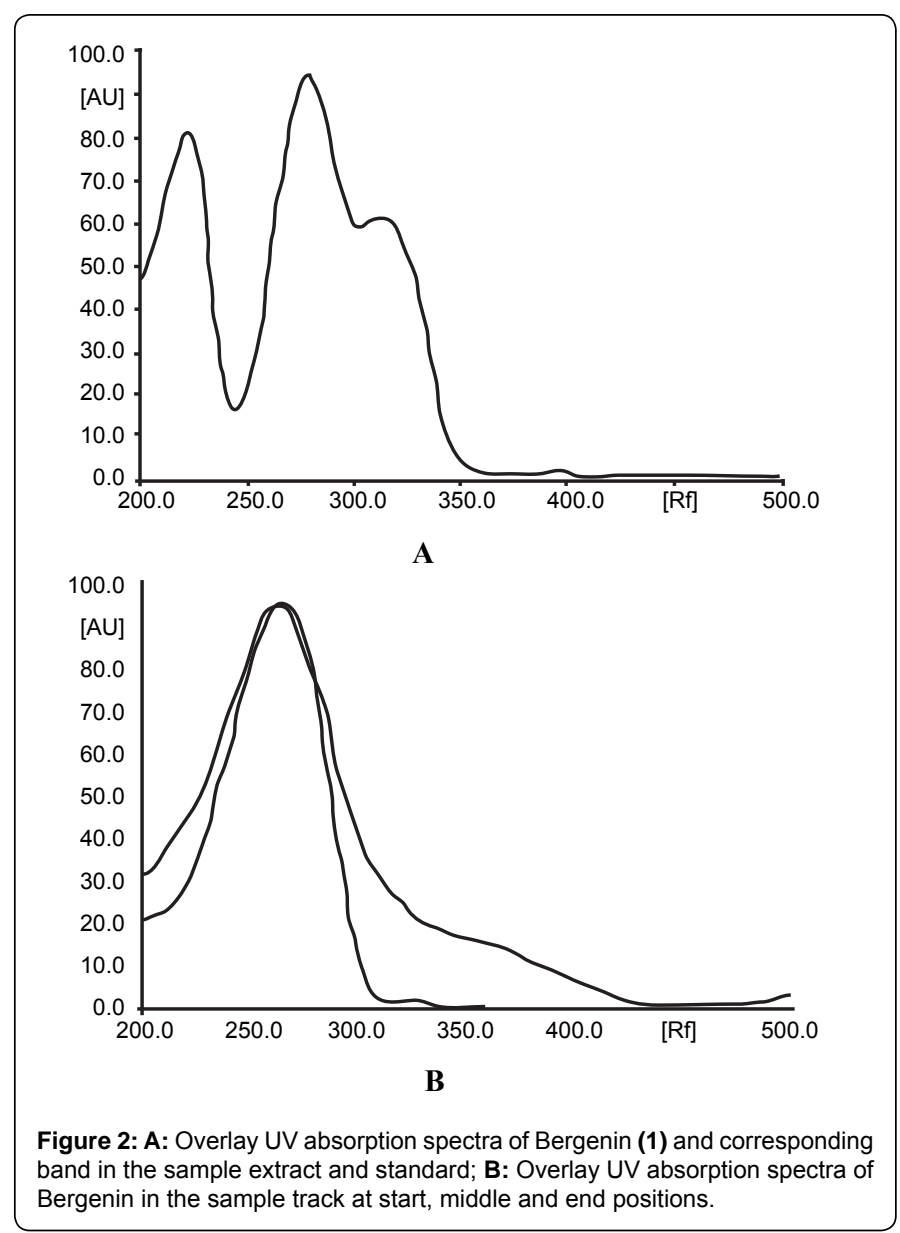


Citation: Dharmender R, Madhavi T, Reena A, Sheetal A (2010) Simultaneous Quantification of Bergenin, (+)-Catechin, Gallicin and Gallic acid; and quantification of $\beta$-Sitosterol using HPTLC from Bergenia ciliata (Haw.) Sternb. Forma ligulata Yeo (Pasanbheda). Pharm Anal Acta 1:104. doi:10.4172/2153-2435.1000104

Page 5 of 9
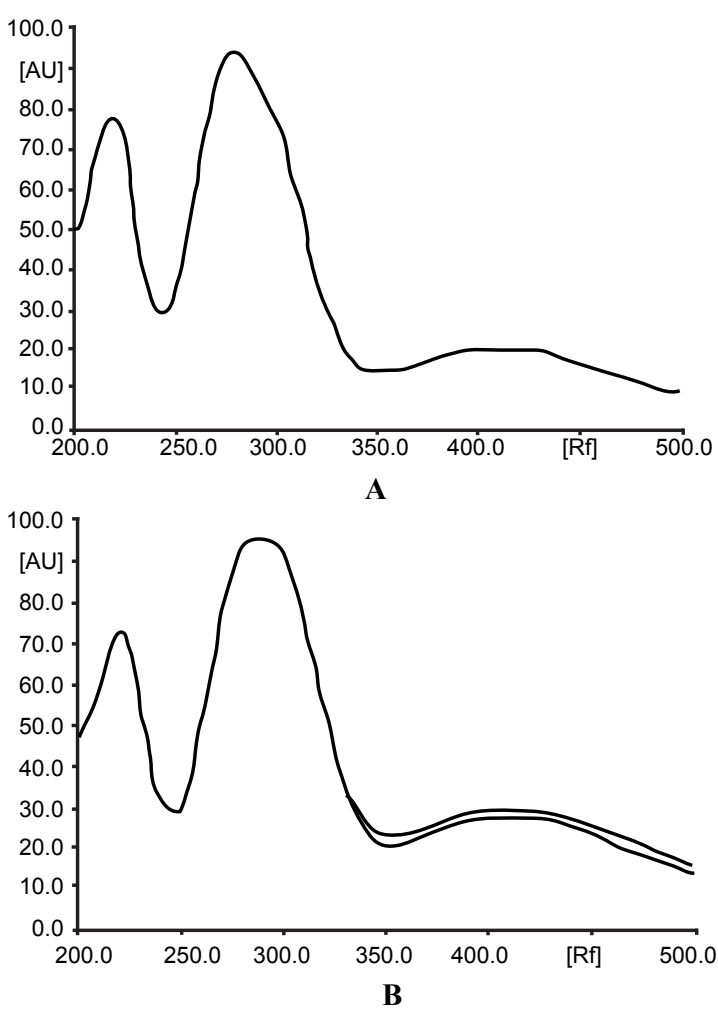

Figure 3: A: Overlay UV absorption spectra of (+)-Catechin (2) and corresponding band in the sample extract and standard; B: Overlay UV absorption spectra of $(+)-$ Catechin in the sample track at start, middle and end positions.

$480 \mathrm{ng} / \mathrm{spot}$ of Gallic acid and $160 \mathrm{ng} / \mathrm{spot}$ of $\beta$-Sitosterol individually on TLC plate $(\mathrm{n}=5)$ and expressed as\% R.S.D.

\section{Inter-day and intra-day variation}

Variability of the method was studied by analyzing aliquots of standard solution containing 400, 480, $560 \mathrm{ng} /$ spot of Bergenin, 400, 480, $560 \mathrm{ng} / \mathrm{spot}$ of (+)-Catechin, 320, 480, $640 \mathrm{ng} / \mathrm{spot}$ of Gallicin, 320, 480, $640 \mathrm{ng} / \mathrm{spot}$ of Gallic acid and 80, 160, $240 \mathrm{ng} / \mathrm{spot}$ of $\beta$-Sitosterol on the same day (intra-day precision) and on different days (inter-day precision) and the results were expressed as\% R.S.D.

\section{Limit of detection and limit of quantification}

For the evaluation of limit of detection and limit of quantification different concentrations of the standard solutions of Bergenin, $(+)$-Catechin, Gallicin, Gallic acid and $\beta$-Sitosterol were applied along with methanol as blank and determined on the basis of signal to noise ratio.

\section{Recovery}

The accuracy of the method was assessed by performing recovery study at three different levels $(50 \%, 100 \%$ and $125 \%$ addition of Bergenin, (+)-Catechin, Gallicin, Gallic acid and $\beta$-Sitosterol). The percent recoveries and the average percent recoveries were calculated for each.

\section{Specificity}

Specificity of the method was carried out as mentioned by Bhandari et al. [64]. Specificity was ascertained by analyzing standard compounds and samples. The bands for glycyrrhizin, glycyrrhetinic acid, apigenin, kaempferol and quercetin from sample solutions were confirmed by comparing the Rf and spectra of the bands to those of the standards. The peak purity of all the compounds (Figure 2, Figure 3 and Figure 4) was analysed by comparing the spectra at three different levels, i.e. start, middle, and end positions of the bands.

\section{Results and Discussion}

B. ciliata is an important plant of Indian System of Medicine. There is no report of simultaneous quantification of Bergenin, (+)-Catechin, Gallicin and Gallic acid. Hence we developed a simple and precise method for quantification of these four marker compounds.

\section{TLC fingerprint and co-chromatography}

Quality control of herbal medicines is a tedious and difficult job. Herbal medicines differ from that of the conventional drugs and so some innovative methods are coming into being for the sake of quality assessment of herbal drugs. Quality control and quality assurance of herbal drugs remains a challenge as they contain a myriad of compounds in complex matrices in which no single active constituent is responsible for the overall efficacy [65].

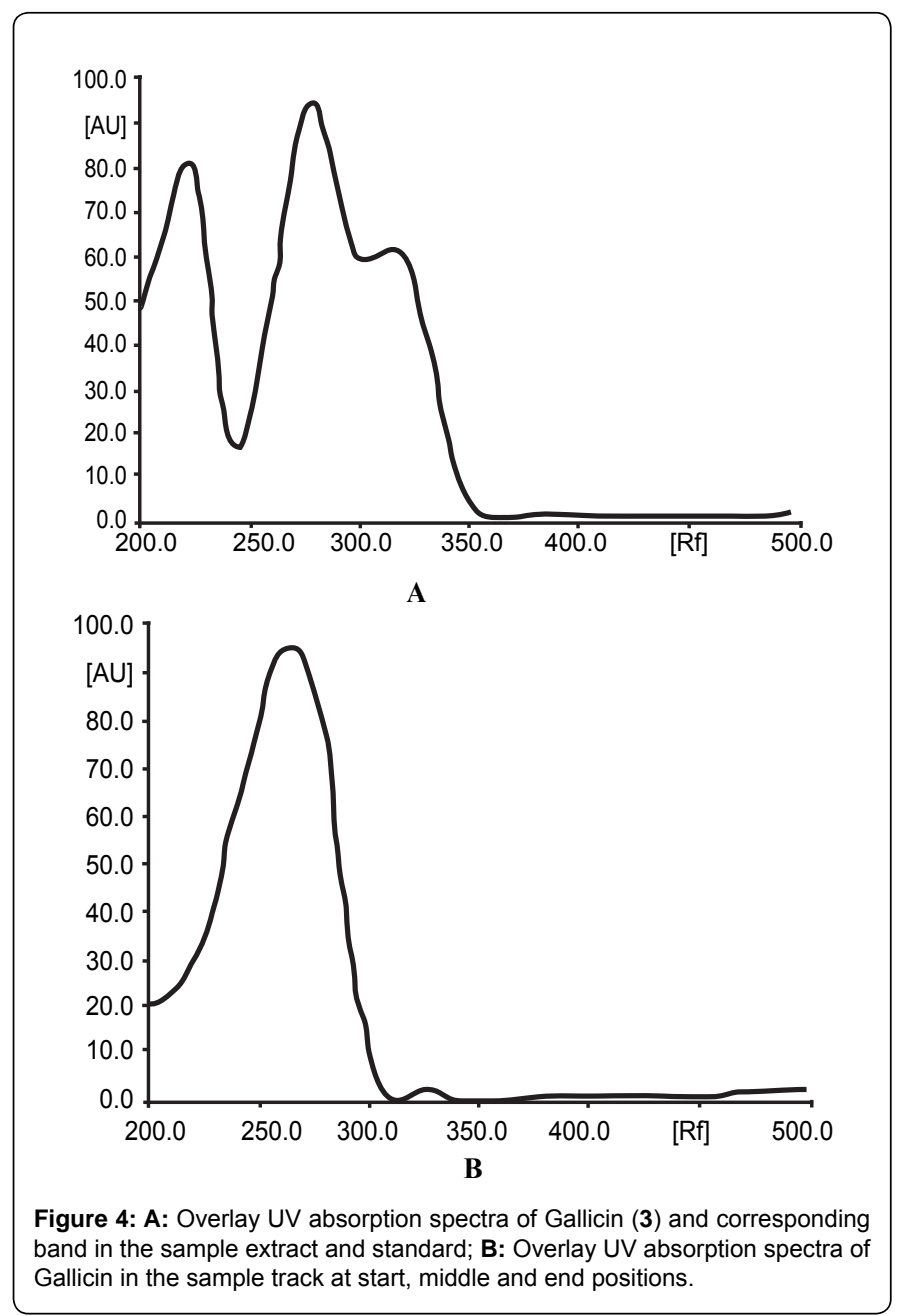


Citation: Dharmender R, Madhavi T, Reena A, Sheetal A (2010) Simultaneous Quantification of Bergenin, (+)-Catechin, Gallicin and Gallic acid; and quantification of $\beta$-Sitosterol using HPTLC from Bergenia ciliata (Haw.) Sternb. Forma ligulata Yeo (Pasanbheda). Pharm Anal Acta 1:104. doi:10.4172/2153-2435.1000104

Page 6 of 9

\begin{tabular}{|l|l|}
\hline$R_{\mathrm{f}}$ values & \\
\hline Sample Solution-A & Sample Solution-B \\
\hline 0.08 & 0.09 \\
\hline 0.13 (Bergenin standard) & 0.13 \\
\hline 0.19 & 0.22 \\
\hline 0.38 & 0.39 \\
\hline 0.49 (+)-Catechin standard) & 0.49 \\
\hline 0.56 (Gallic acid standard) & 0.56 \\
\hline 0.64 (Gallicin standard) & 0.64 \\
\hline 0.71 & 0.74 \\
\hline 0.78 & 0.78 \\
\hline
\end{tabular}

Table 1: TLC fingerprinting profile Bergenia ciliata rhizomes (Sample Solution-A and Sample Solution-B, Solvent System-1) under UV 254nm.
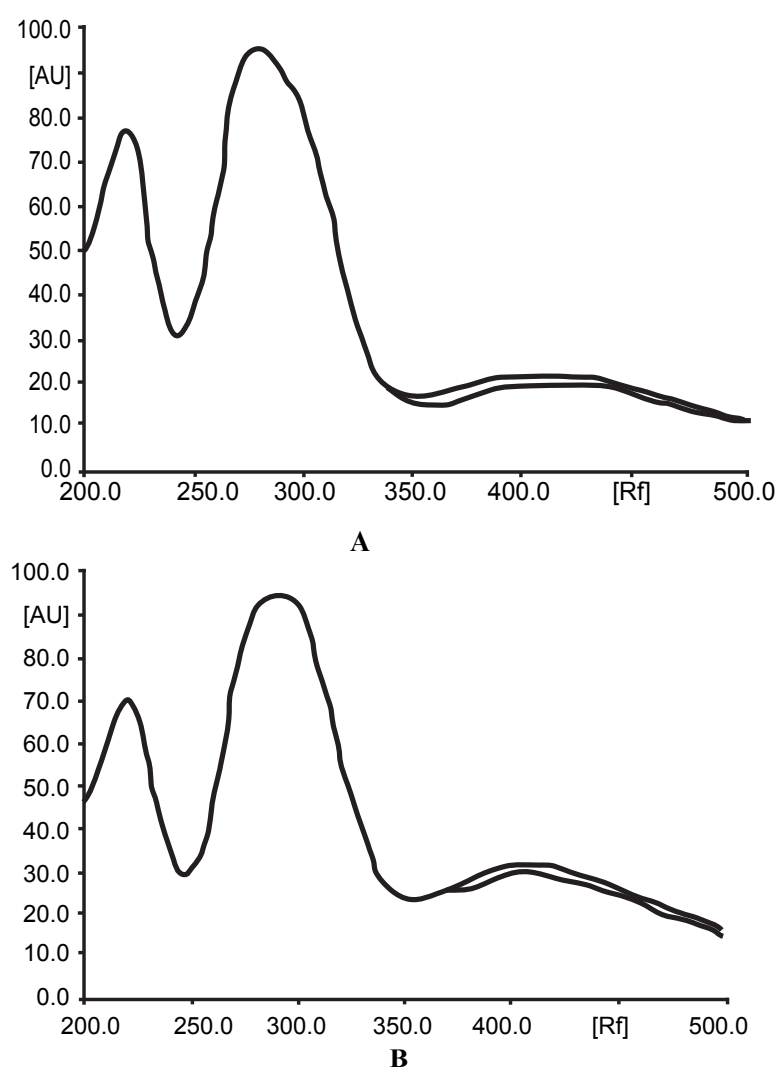

Figure 5: A: Overlay UV absorption spectra of Gallic acid (4) and corresponding band in the sample extract and standard; B: Overlay UV absorption spectra of Gallic acid in the sample track at start, middle and end positions.

Fingerprint analysis approach using chromatography has become the most potent tools for quality control of herbal medicines because of its simplicity and reliability. It can serve as a tool for identification, authentication and quality control of herbal drugs. The construction of chromatographic fingerprints plays an important role in the quality control of complex herbal medicines [66]. Chemical fingerprints obtained by chromatographic techniques are strongly recommended for the purpose of quality control of herbal medicines, since they might represent appropriately the "chemical integrities" of the herbal medicines and therefore be used for authentication and identification of the herbal products. Based on the concept of phytoequivalence, the chromatographic fingerprints of herbal medicines could be utilized for addressing the problem of quality control of herbal medicines [67].

Hence a systematic consideration of all its phytoconstituents is as important as the quantification of the active constituents present in it. TLC fingerprint profile of herbal drugs represents a comprehensive qualitative approach for the purpose of species authentication, evaluation of quality and ensuring the consistency and stability of herbal drugs and their products. Literature survey revealed that some work using HPTLC has been reported on this plant. The method reported by Chauhan et al. [31] is less sensitive as the range was in micrograms, while the methods reported by Dhalwal et al. [35] and Srivastava et al. [32] were not able to simultaneously quantify all the four biomarkers. Other methods reported were more tedious and time consuming either done by LC-MS/MS, HPLC or by HPLC MS/MS. In the present study, we developed TLC fingerprint profile

\begin{tabular}{|l|l|l|l|l|l|l|}
\hline $\begin{array}{l}\text { Sr. } \\
\text { No. }\end{array}$ & Parameter & Bergenin & $(+)$-Catechin & Gallicin & $\begin{array}{l}\text { Gallic } \\
\text { acid }\end{array}$ & $\beta$-Sitosterol \\
\hline 1 & $\begin{array}{l}\text { Instrumental } \\
\text { precision } \\
(\% \text { CV, } \mathrm{n}=7)\end{array}$ & 3.29 & 3.36 & 3.05 & 1.20 & 0.85 \\
\hline 2 & $\begin{array}{l}\text { Repeatability } \\
(\% \text { CV, } \mathrm{n}=5)\end{array}$ & 1.95 & 1.83 & 1.15 & 1.12 & 1.51 \\
\hline 4 & $\begin{array}{l}\text { Accuracy } \\
\text { (average } \% \\
\text { recovery) }\end{array}$ & 100.38 & 101.45 & 102.38 & 99.9 & 99.92 \\
\hline 5 & $\begin{array}{l}\text { Limit of } \\
\text { detection } \\
\text { (ng) }\end{array}$ & 60 & 60 & 48 & 64 & 20 \\
\hline 6 & $\begin{array}{l}\text { Limit of } \\
\text { quantification } \\
\text { (ng) }\end{array}$ & 160 & 160 & 112 & 112 & 60 \\
\hline 7 & Specificity & Specific & Specific & Specific & Specific & Specific \\
\hline 8 & $\begin{array}{l}\text { Linearity } \\
\text { (Correlation } \\
\text { coefficient) }\end{array}$ & 0.999 & 0.997 & 0.998 & 0.996 & 0.995 \\
\hline 9 & $\begin{array}{l}\text { Range (ng/ } \\
\text { spot) }\end{array}$ & $160-720$ & $160-720$ & $160-720$ & $\begin{array}{l}160- \\
720\end{array}$ & $80-480$ \\
\hline
\end{tabular}

Table 2: Method validation parameters for the quantification of Bergenin $(+)$-Catechin, Gallicin, Gallic acid and $\beta$-Sitosterol by the proposed TLC densitometric methods.

\begin{tabular}{|l|l|l|l|}
\hline Marker & $\begin{array}{l}\text { Concentration } \\
\text { (ng/ spot) }\end{array}$ & Intra-day precision* & Inter-day precision* \\
\hline \multirow{4}{*}{ Bergenin } & 400 & 3.12 & 3.15 \\
\cline { 2 - 4 } & 480 & 2.62 & 1.90 \\
\cline { 2 - 4 } & 560 & 4.26 & 4.27 \\
\hline \multirow{4}{*}{$(+)$-Catechin } & 400 & 1.04 & 0.85 \\
\cline { 2 - 4 } & 480 & 2.5 & 3.05 \\
\cline { 2 - 4 } & 560 & 0.35 & 2.43 \\
\hline \multirow{4}{*}{ Gallicin } & 320 & 1.83 & 0.97 \\
\cline { 2 - 4 } & 480 & 1.20 & 1.25 \\
\cline { 2 - 4 } & 640 & 0.61 & 1.45 \\
\hline \multirow{4}{*}{ Gallic acid } & 320 & 1.56 & 0.64 \\
\cline { 2 - 4 } & 480 & 1.57 & 1.27 \\
\cline { 2 - 4 } & 640 & 1.14 & 0.58 \\
\hline \multirow{3}{*}{ S-Sitosterol } & 80 & 0.15 & 0.26 \\
\cline { 2 - 4 } & 160 & 0.52 & 0.61 \\
\cline { 2 - 4 } & 240 & 0.46 & \\
\hline
\end{tabular}

*\% R.S.D.; Mean $(\mathrm{n}=3)$

Table 3: Intra-day and Inter-day precision of Bergenin, (+)-Catechin, Gallicin, Gallic acid, and $\beta$-Sitosterol. 
Citation: Dharmender R, Madhavi T, Reena A, Sheetal A (2010) Simultaneous Quantification of Bergenin, (+)-Catechin, Gallicin and Gallic acid; and quantification of $\beta$-Sitosterol using HPTLC from Bergenia ciliata (Haw.) Sternb. Forma ligulata Yeo (Pasanbheda). Pharm Anal Acta 1:104. doi:10.4172/2153-2435.1000104

for B. ciliata and carried out co-chromatography with five marker compounds viz. Bergenin, (+)-Catechin, Gallicin, Gallic acid and $\beta$-Sitosterol. The developed methods were further validated and used for the quantification of these compounds. Different sample solutions and solvent systems were tried in order to resolve the marker compounds.

Bergenin, (+)-Catechin, Gallicin and Gallic acid resolved well at $R_{f}$ $0.13,049,0.56$ and 0.64 (Table 1, Figure 1) from sample Solution A and B when the plate was developed in Solvent System-I. The identity of the band for Bergenin, (+)-Catechin, Gallicin and Gallic acid in the sample extract was confirmed by overlaying their UV absorption spectra with those of respective reference standards using CAMAG TLC scanner 3 with WINCATS software (Figure 2A, Figure 3A, Figure $4 \mathrm{~A}$ and Figure $5 \mathrm{~A})$. The purity of each of these bands in the sample extract was confirmed by comparing the absorption spectra recorded at start, middle and end positions of the band (Figure 2B, Figure 3B, Figure $4 B$ and Figure $5 B$ ). $\beta$-Sitosterol resolved at $R_{f} 0.50$ along with one more compound from Sample Solution A when the plate was developed in Solvent System-II and derivatized as mentioned.

Preliminary TLC and co-TLC indicated the possible presence of Bergenin, (+)-Catechin, Gallicin, Gallic acid and $\beta$-Sitosterol in $B$. ligulata. Hence, we quantified these five compounds from $B$. ligulata.

\section{TLC densitometric quantification of bergenin, (+)-catechin,} gallicin, gallic acid and $\beta$-Sitosterol using HPTLC

The simplicity of the sample preparation, and the possibility of analyzing several sample of herbal products simultaneously in a short time, make HPTLC the method of choice. In the present work five compounds viz. Bergenin, (+)-Catechin, Gallicin, Gallic acid and

\begin{tabular}{|c|c|c|c|c|c|}
\hline Marker & $\begin{array}{l}\text { Amount } \\
\text { of marker } \\
\text { present } \\
(\mu \mathrm{g})\end{array}$ & $\begin{array}{l}\text { Amount } \\
\text { of marker } \\
\text { added } \\
(\mu \mathrm{g})\end{array}$ & $\begin{array}{l}\text { Amount of } \\
\text { marker found } \\
(\mu \mathrm{g})\end{array}$ & $\begin{array}{l}\text { Recovery* } \\
(\%)\end{array}$ & $\begin{array}{l}\text { Average } \\
\text { Recovery } \\
(\%)\end{array}$ \\
\hline \multirow{3}{*}{ Bergenin } & 110 & 55 & $160.25 \pm 3.50$ & $97.12 \pm 0.73$ & \multirow{3}{*}{100.38} \\
\hline & 110 & 110 & $222.5 \pm 7.23$ & $101.13 \pm 1.18$ & \\
\hline & 110 & 140 & $255.23 \pm 4.71$ & $102.9 \pm 1.02$ & \\
\hline \multirow{3}{*}{ (+)-Catechin } & 60 & 30 & $92.37 \pm 4.58$ & $102.63 \pm 0.96$ & \multirow{3}{*}{101.45} \\
\hline & 60 & 60 & $118.91 \pm 7.25$ & $99.09 \pm 1.20$ & \\
\hline & 60 & 75 & $138.59 \pm 2.17$ & $102.65 \pm 0.64$ & \\
\hline \multirow{3}{*}{ Gallicin } & 40 & 20 & $60.89 \pm 1.21$ & $101.48 \pm 0.52$ & \multirow{3}{*}{102.38} \\
\hline & 40 & 40 & $83.05 \pm 4.15$ & $103.81 \pm 0.87$ & \\
\hline & 40 & 50 & $91.68 \pm 3.17$ & $101.86 \pm 0.69$ & \\
\hline \multirow{3}{*}{ Gallic acid } & 252 & 125 & $376.54 \pm 3.21$ & $99.87 \pm 0.73$ & \multirow{3}{*}{99.9} \\
\hline & 252 & 252 & $504.72 \pm 2.31$ & $100.14 \pm 0.58$ & \\
\hline & 252 & 316 & $566.25 \pm 3.37$ & $99.69 \pm 0.76$ & \\
\hline \multirow{3}{*}{$\beta$-Sitosterol } & 45 & 22 & $67.54 \pm 4.71$ & $100.81 \pm 1.05$ & \multirow{3}{*}{99.92} \\
\hline & 45 & 45 & $89.75 \pm 7.14$ & $99.72 \pm 1.19$ & \\
\hline & 45 & 54 & $98.23 \pm 3.13$ & $99.22 \pm 0.87$ & \\
\hline
\end{tabular}

*Mean \pm SD $(n=3)$

Table 4: Recovery studies of Bergenin, (+)-Catechin, Gallicin, Gallic acid and $\beta$-Sitosterol at $50 \%, 100 \%$ and $125 \%$ addition by the proposed TLC densitometric method.

\begin{tabular}{|l|l|l|l|l|l|}
\hline $\begin{array}{l}\text { Sample } \\
\text { Solution }\end{array}$ & $\begin{array}{l}\text { Bergenin } \\
(\% \mathrm{w} / \mathrm{w})^{*}\end{array}$ & $\begin{array}{l}(+) \text {-Catechin } \\
(\% \mathrm{w} / \mathrm{w})^{*}\end{array}$ & $\begin{array}{l}\text { Gallicin } \\
(\% \mathrm{w} / \mathrm{w})^{*}\end{array}$ & $\begin{array}{l}\text { Gallic acid } \\
(\% \mathrm{w} / \mathrm{w})^{*}\end{array}$ & $\begin{array}{l}\beta \text {-Sitosterol } \\
(\% \mathrm{w} / \mathrm{w})^{*}\end{array}$ \\
\hline A & $0.11 \pm 0.0026$ & $0.048 \pm 0.007$ & $0.036 \pm 0.003$ & $0.022 \pm 0.002$ & $\mathrm{NQ}$ \\
\hline B & $0.22 \pm 0.0026$ & $0.063 \pm 0.004$ & $\mathrm{NQ}$ & $0.25 \pm 0.003$ & $\mathrm{NQ}$ \\
\hline C & $\mathrm{NQ}$ & $\mathrm{NQ}$ & $\mathrm{NQ}$ & $\mathrm{NQ}$ & $0.044 \pm 0.031$ \\
\hline
\end{tabular}

${ }^{*}$ Mean \pm S.D. $(n=3) ; N Q=$ Not quantified

Table 5: Bergenin, (+)-Catechin, Gallicin, Gallic acid and $\beta$-Sitosterol content estimated in Bergenia ciliata by proposed TLC densitometric method.

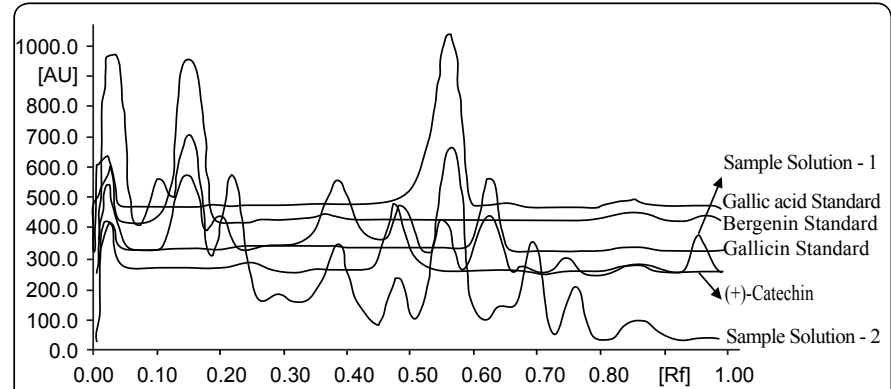

Figure 6: TLC densitometric chromatogram at $280 \mathrm{~nm}$ of Sample Solutions-1 and -2 of Bergenia ciliata Rhizomes.

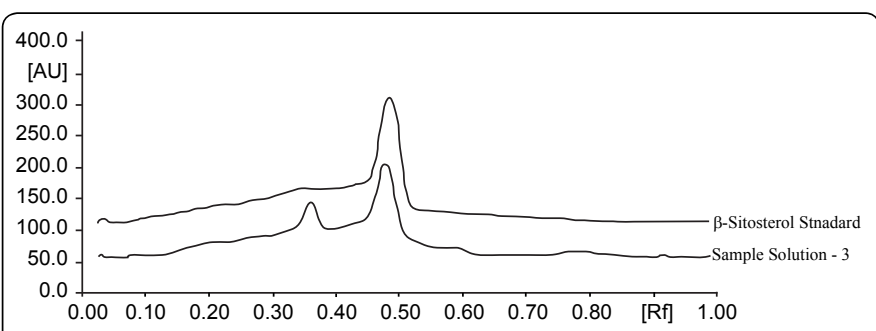

Figure 7: TLC densitometric chromatogram at $525 \mathrm{~nm}$ of Sample Solution-3 of Bergenia ligulata Rhizomes.

-Sitosterol were quantified from B. ciliata by TLC densitometric methods using HPTLC. For the quantification of Bergenin and (+)-Catechin, TLC densitometric method was established and described. For the quantification of Gallicin, Gallic acid [59-63] and $\beta$-Sitosterol [63], methods reported by us earlier were adopted with modifications to suit the sample.

The TLC densitometric methods were validated in terms of precision, repeatability, and accuracy (Table 2, Table 3 and Table 4). The linearity ranges for Bergenin, (+)-Catechin, Gallicin and Gallic acid were found to be the same (160-720 ng/spot) with correlation coefficients ( $r$-values) of $0.999,0.997,0.998$ and 0.996 respectively (Table 2 ). The linearity range for $\beta$-Sitosterol was 80-480 ng/spot with correlation coefficient ( $r$-values) of 0.995 . The TLC densitometric methods were found to be precise with R.S.Ds for intraday in the range of 2.62-4.26, 0.35-2.5, 0.61-1.83, $1.14-1.57$ and $0.15-0.52$ and for interday in the range of 1.90 $4.27,0.85-3.05,0.97-1.45,0.58-1.27$ and $0.26-0.61$ for different concentrations of Bergenin, (+)-Catechin, Gallicin, Gallic acid and -Sitosterol respectively (Table 3). This indicates that the proposed methods were precise and reproducible. The limit of detection (LOD) values for Bergenin, (+)-Catechin, Gallicin, Gallic acid and $\beta$-Sitosterol were found to be $60,60,48,64$ and $20 \mathrm{ng}$, respectively, and limit of quantification (LOQ) values were 160, 160, 160, 160 and $80 \mathrm{ng}$, respectively (Table 2). The average percent recoveries at 3 different levels of Bergenin, (+)-Catechin, Gallicin, Gallic acid and $\beta$-Sitosterol were found to be 100.38, 101.45, 102.38, 99.9 and 99.92\%, respectively (Table 4).

Bergenin,(+)-Catechin, Gallicin and Gallicacid were simultaneously quantified from Sample Solution-1 and -2 . The amount of Bergenin, (+)-Catechin, Gallicin and Gallic acid were found to be $0.11,0.048$, 0.036 and $0.022 \% \mathrm{w} / \mathrm{w}$ respectively in Sample Solution-1(Table 5, Figure 6). Bergenin is reported to be present in glycoside form in B. cilita $[12,13]$. Gallic acid is known to be present in ester form in plant materials (polygalloyl ester chains of gallotannins) [68]. $(+)$-Catechin is also present in bound form as (+)-Catechin-3-gallate 
Citation: Dharmender R, Madhavi T, Reena A, Sheetal A (2010) Simultaneous Quantification of Bergenin, (+)-Catechin, Gallicin and Gallic acid; and quantification of $\beta$-Sitosterol using HPTLC from Bergenia ciliata (Haw.) Sternb. Forma ligulata Yeo (Pasanbheda). Pharm Anal Acta 1:104. doi:10.4172/2153-2435.1000104

Page 8 of 9

[16] and (+)-Catechin-7-O- $\beta-D$-glucopyranoside [12]. Hence we hydrolyzed the sample (Sample Solution-2) and quantified bergenin, $(+)$-Catechin and Gallic acid from the same. After hydrolysis, the amount of Bergenin, (+)-Catechin and Gallic acid was found to be $0.22,0.063$ and $0.25 \% \mathrm{w} / \mathrm{w}$ respectively (Table 5, Figure 6). Gallicin was present in Sample Solution-2 but not in detectable amount.

For quantification of $\beta$-Sitosterol petroleum ether extract was prepared to minimize the interference by other compounds. The content of $\beta$-Sitosterol quantified using TLC densitometric method was found to be $0.044 \% \mathrm{w} / \mathrm{w}$ (Table 5, Figure 7).

\section{Conclusion}

We established TLC densitometric method for the simultaneous quantification of four bioactive compounds viz. Bergenin, $(+)$-Catechin, Gallicin and Gallic acid and quantification of $\beta$-Sitosterol from rhizomes of $B$. ciliata using HPTLC. The method was found to be simple, precise, specific sensitive and accurate and can also be used for the quantification of Bergenin, (+)-Catechin, Gallicin, Gallic acid and $\beta$-Sitosterol in the herbal raw materials. It can also be used in routine quality control of herbal materials as well as formulations containing any or all of these compounds.

\section{Acknowledgement}

We thank Prof. Harish Padh, Project Director, NIPER-Ahmedabad for providing the infrastructure, funds and facilities for the completion of the work.

\section{References}

1. Reddy UDC, Chawla AS, Deepak M, Singh D, Handa SS (1999) High pressure liquid chromatographic determination of Bergenin and (+)-Afzelechin from different parts of Paashaanbhed (Bergenia ligulata Yeo). Phytochemical Analysis 10: 44-47.

2. Anonymous (1948) The Wealth of India, Raw materials, Vol 1, Council of Scientific and Industrial Research (CSIR). New Delhi: 179.

3. Khare CP (2007) Indian Medicinal Plants, An illustrated Dictionary, Springer Science. New York: 90.

4. Ashokar LV, Kakkar KK, Chakra OJ (1992) Glossary of Indian Medicinal Plants with Active Principles, Publication and Information Directorate. New Delhi: 122.

5. Kirtikar KR, Basu BD (1975) Indian medicinal plants, Vol 2, Bishen Singh Mahendra Pal Singh, Dehradun. India 993-994.

6. Nadkarni KM (1976) Indian Materia Medica, Vol 1, Popular Prakashan, Bombay. India 1113.

7. Manandhar NP (1995) Medicinal folk-lore about the plants used as anthelmintic agents in Nepal. Fitoterapia 66: 149-155.

8. Prasad KVSRG, Sujatha D, Bharathi K (2007) Herbal drugs in Urolithiasis- A Review. Pharmacognosy Reviews 1: 176-179.

9. Gehlot NK, Sharma VN, Vyas DS (1976) Some pharmacological studies on ethanolic extract of Bergenia ligulata. Indian Journal of Pharmacology 8: 92.

10. Sinha S, Murugesan T, Pal M, Saha BP (2001) Evaluation of antitussive activity of Bergenia ciliata Sternb. Rhizome extract in mice. Phytomedicine 8: 298-301.

11. Sinha S, Murugesan T, Maiti K, Gayen JR, Pal B, et al. (2001) Antibacterial activity of Bergenia ciliata rhizome. Fitoterapia 72: 550-552.

12. Vaishali AS, Vikas MD, Krishnapriya M, Sanjeevani G (2008) Identification of potential antioxidants by in-vitro activity guided fractionation of Bergenia ligulata. Pharmacognosy Magazine 4: 79-84

13. Dixit BS, Srivastava SN (1989) Tannin constituents of Bergenia ligulata roots. Indian Journal of Natural Products 5: 24-25.

14. Haslam E (1969) (+)-Catechin-3-gallate, a polymeric proanthocyanidin from Bergenia species. J Chem Soc C 1969: 1824-1828.

15. Reddy UDC, Chawla AS, Deepak M, Maurya R, Handa SS (1998) Paashaanolactone from Bergenia ligulata. Phytochemistry 47: 907-909.

16. Bahl CP, Murari R, Parthasarathy MR, Seshadri TR (1974) Components of Bergenia strecheyi and Bergenia ligulata. Indian J Chem 12: 1038-1039.
17. Tucci PA, Delle MF, Marini B, Holo BG (1969) Occurrence of (+) -afzelchin in Saxifraga ligulata Ann. 1st Super Sanita 5: 555-556.

18. Sethi PD (1992) Identification of Drugs in Pharmaceutical Formulations by Thin Layer Chromatography. CBS Publishers, New Delhi.

19. Watanabe T, Terabe S (2000) Analysis of natural food pigments by capillary electrophoresis. J Chromatogr A 880: 311-322.

20. Singh N, Gupta AP, Singh B, Kaul VK (2005) Quantification of Picroside-I and Picroside-II in Picrorhiza kurroa by HPTLC. J Liq Chromatogr Relat Technol 28: 1679-1691.

21. Mishra N, Gupta AP, Singh B, Kaul VK, Ahuja PS (2005) A Rapid Determination of Podophyllotoxin in Podophyllum hexandrum by Reverse Phase High Performance Thin Layer Chromatography. J Liq Chromatogr Relat Technol 28: 677-691.

22. Bhandari P, Gupta AP, Singh B, Kaul VK (2005) Simultaneous densitometric determination of artemisinin, artemisinic acid and arteannuin-B in Artemisia annua using reversed-phase thin layer chromatography. J Sep Sci 28: 22882292.

23. Bhandari P, Gupta AP, Singh B, Kaul VK (2006) HPTLC determination of swertiamarin and amarogentin in Swertia species from the western Himalayas. Journal of Planar Chromatography-Modern TLC 19: 212-215.

24. Bhandari P, Kumar N, Gupta AP, Singh B, Kaul VK (2006) Micro-LC Determination of Swertiamarin in Swertia species and Bacoside-A in Bacopa monnieri. Chromatographia 64: 599-602.

25. Stuppner H, Wagner $H$ (1992) HPLC und DC-Untersuchungen von iridoids, Cucurbitacin und Phenol-Giykosiden aus Picrorhiza kurroa. Scientia Pharmaceutica 60: 73-85.

26. Dwivedi AK, Kulkarani D, Singh S (1997) Sensitive high-performance liquid chromatographic assay method for determination of Picroside-I in plasma. Chromatogr B Analyt 698: 317-320.

27. Gupta AP, Gupta MM, Kumar S. (1999) Estimation of tropane alkaloids using high performance thin layer chromatography. Journal of Indian Chemistry Society 76: 277-278.

28. Gupta AP, Gupta MM, Kumar S (1999) Simultaneous determination of curcuminoids in Curcuma samples using high performance thin layer chromatography. J Liq Chromatogr Relat Technol 22: 1561-1569.

29. Gupta AP, Verma RK, Gupta, MM, Kumar S (1999) Estimation of plumbagin using high performance thin layer chromatography. Journal of Medicinal and Aromatic Plant Sciences 21: 661-663.

30. Gupta AP, Gupta MM, Kumar S (1999) HPTLC of asiaticoside in Centella asiatica. Journal of Indian Chemistry Society 76: 321-322.

31. Chauhan SK, Singh B, Agrawal S (2000) Simultaneous Determination of Bergenin and Gallic Acid in Bergenia ligulata Wall by High-Performance ThinLayer Chromatography. J AOAC Int 83: 1480-1483.

32. Srivastava S, Rawat AKS (2007) Simultaneous determination of bergenin and gallic acid in different Bergenia species. Journal of Planar Chromatography 20: 275-277.

33. Yu W, Wang Y, Zhang Y, Zhang D, Lan J, et al. (2009) Quantitation of bergenin in human plasma by liquid chromatography/tandem mass spectrometry. $J$ Chromatogr B Analyt Technol Biomed Life Sci B 877: 33-36.

34. Reddy UDC, Chawla AS, Deepak M, Singh D, Handa (1999) High Pressure Liquid Chromatographic Determination of Bergenin and (+) -Afzelechin from Different Parts of Paashaanbhed (Bergenia ligulata Yeo). Phytochemical Analysis 10: 44-47.

35. Dhalwal K, Shinde VM, Biradar YS, Mahadik KR. (2008) Simultaneous quantification of bergenin, catechin, and gallic acid from Bergenia ciliata and Bergenia ligulata by using thin-layer chromatography. J Food Compost Anal 21 : 496-500.

36. Shi YB, Shi YP, Meng QG (2006) Determination and pharmacokinetic study of bergenin in rat plasma by RP-HPLC method. BMC. Biomedical chromatography 20: $1065-1070$.

37. Wang J, Wang BJ, Wei CM, Yuan GY, Zhang R, et al. (2009) Determination of bergenin in human plasma after oral administration by HPLC MS/MS and its pharmacokinetic study. Biomed chromatogr 23: 199-203.

38. Nunomura RCS, Oliveira VG, Silvab SLD, Nunomuraa SM (2009) Characterization of Bergenin in Endopleura uchi Bark and its Anti-Inflammatory Activity. J Braz Chem Soc 20: 1060-1064. 
Citation: Dharmender R, Madhavi T, Reena A, Sheetal A (2010) Simultaneous Quantification of Bergenin, (+)-Catechin, Gallicin and Gallic acid; and quantification of $\beta$-Sitosterol using HPTLC from Bergenia ciliata (Haw.) Sternb. Forma ligulata Yeo (Pasanbheda). Pharm Anal Acta 1:104. doi:10.4172/2153-2435.1000104

39. Singh DP, Srivastava SK, Govindarajan R, Rawat AKS (2007) HighPerformance Liquid Chromatographic Determination of bergenin in different bergenia species. Acta Chromatographica 19: 246-252.

40. Lim HK, Kim HS, Choi HS, Choi J, Kim SH, et al. (2001) Effects of Bergenin, the major constituent of Mallotus japonicus against D-Galactosamine induced hepatotoxicity in rats. Pharmacology 63: 71-75

41. Nazir N, Koul S, Qurishi MA, Taneja SC, Ahmad SF, et al. (2007) Immunomodulatory effect of bergenin and norbergenin against adjuvant induced arthritis-A flow cytometric study. J Ethnopharmaco 112: 401-405.

42. Dobashi Y, Hiranoa T, Hiranoa M, Ohkatsua Y (2008) Antioxidant and photo antioxidant abilities of Catechin. J Photochem Photobiol A Chem 197: 141-148.

43. Gamberucci A, Konta L, Colucci A, Giunti R, Magyar JE, et al. (2006) Green tea flavanols inhibit glucosidase II. Biochem Pharmacol 72: 640-646.

44. Demeule M, Brossard M, Page M, Gingras D, Beliveau R (2000) Matrix Metalloproteinase inhibition by green tea catechins. Biochim Biophys Acta 1478: $51-60$

45. Chander V, Singh D, Chopra K (2003) Catechin, a natural antioxidant protects against rhabdomyolysis-induced myoglobinuric acute renal failure. Pharmacol Res 48: 503-509.

46. Kuzuharaa T, Suganumab M, Fujikia H (2008) Green tea catechin as a chemical chaperone in cancer prevention. Cancer Lett 261: 12-20.

47. Kumaran A, Karunakaran RJ (2006) Nitric oxide radical scavenging active components from Phyllanthus emblica L. Plant Foods Hum Nutr 61: 1-5.

48. Bailey AE, Asplund RO, Ali MS (1986) Isolation of methyl gallate as the antitumor principle of Acer saccharinum. J Nat Prod 49: 1149-1150.

49. Lim MY, Park YH, Son DJ, Kim MK, Lee HS (2004) Antiplatelet activity of gallic acid and methyl gallate. Food Sci Biotechnol 13: 806-809.

50. Rivero-Cruz JF (2008) Antimicrobial compounds isolated from Haematoxylon brasiletto. J Ethnopharmacol 119: 99-103.

51. Kim SJ, Jin M, Lee E, Moon TC, Quan Z, et al. (2006) Effects of methyl gallate on arachidonic acid metabolizing enzymes: cyclooxygenase-Il and 5-lipoxygenase in mouse bone marrow derived mast cells. Archives of Pharmacy Research 29: 874-878.

52. Westenberg HE, Lee KJ, Lee SK, Fong HH, Breemen RB V, et al. (2000) Activity-Guided Isolation of Antioxidative Constituents of Cotinus coggygria. $J$ Nat Prod 63: 1696-1698.

53. Haslam E (1996) Natural Polyphenols (Vegetable Tannins) as Drugs: Possible Modes of Action. J Nat Prod 59: 205-215.

54. Liu Z, Schwimer J, Liu D, Lewis J, Greenway FL, et al. (2006) Gallic acid is partially responsible for antiangiogenic activities of Rubus leaf extract, Phytother Res 20: 806-813.
55. Vivancos M, Moreno JJ (2005) $\beta$-Sitosterol modulates antioxidant enzyme response in RAW 264.7 macrophages. Free Radical and Biological Medicines 39: 91-97.

56. Delporte C, Backhouse N, Erazo S, Negrete R, Vidal P, et al. (2005) Analgesicantiinflammatory properties of Proustia pyrifolia. J Ethnopharmacol 99: 119124

57. McAnuff MA, Harding WW, Omoruyi FO, Jacobs H, Morrison EY, et al. (2005) Hypoglycemic effects of steroidal sapogenins isolated from Jamaican Bitter yam (Dioscorea polygonides). Food Chem Toxicol 43: 1667-1672.

58. Klippel KF, Hiltl DM, Schipp B (1997) A multicentric, placebo-controlled, double-blind clinical trial of $\beta$-sitosterol (phytosterol) for the treatment of benign prostatic hyperplasia. Br J Urol 80: 427-432.

59. Anandjiwala S, Srinivasa $H$, Rajani M (2007) Isolation and TLC densitometric quantification of gallicin, gallic acid, lupeol and $\beta$-sitosterol from Bergia suffruticosa, a hitherto unexplored plant. Chromatographia 66: 725-734.

60. Bagul MS, Ravishankara MN, Padh H, Rajani M (2003) Phytochemical evaluation and free radical scavenging properties of rhizomes of Bergenia ciliata. Journal of Natural Remedies 3: 83-89.

61. Pathak SB, Niranjan K, Padh H, Rajani M (2004) TLC densitometric method for the quantification of eugenol and gallic acid in clove. Chromatographia 60 : 241-244.

62. Bagul MS, Srinivasa H, Padh H, Rajani M (2005) A rapid densitometric method for simultaneous quantification of gallic acid and ellagic acid in herbal raw materials using HPTLC. J Sep Sci 28: 581-584.

63. Dhalwal K, Biradar YS, Rajani M (2006) High-performance thin-laye chromatography densitometric method for simultaneous quantification of phyllanthin, hypophyllanthin, gallic acid and ellagic acid in Phyllanthus amarus. J AOAC Int 89: 619-623.

64. Bhandari P, Kumar N, Gupta AP, Singh B, Kaul VK (2007) A rapid RP-HPTLC densitometry method for simultaneous determination of major flavonoids in important medicinal plants. J Sep Sci 30: 2092- 2096.

65. World Health Organization (WHO), WPR/RC52/7 (2001) A draft regiona strategy for Traditional Medicine in western pacific. WHO Regional committee, 52nd session Darussalam, 10-14 Sept.

66. Gong F, Liang YZ, Xie PS, Chau FT (2003) Information theory applied to chromatographic fingerprint of herbal medicine for quality control. J Chromatogr A 1002: 25-40.

67. Liang YZ, Xie P, Chan K (2004) Quality control of herbal medicines. J Chromatogr B Analyt Technol Biomed Life Sci 812: 53-70.

68. Evans WC (2002) Pharmacognosy. 15th Ed. Elsevier Science Ltd, W. B Saunders, London, 221-224. 